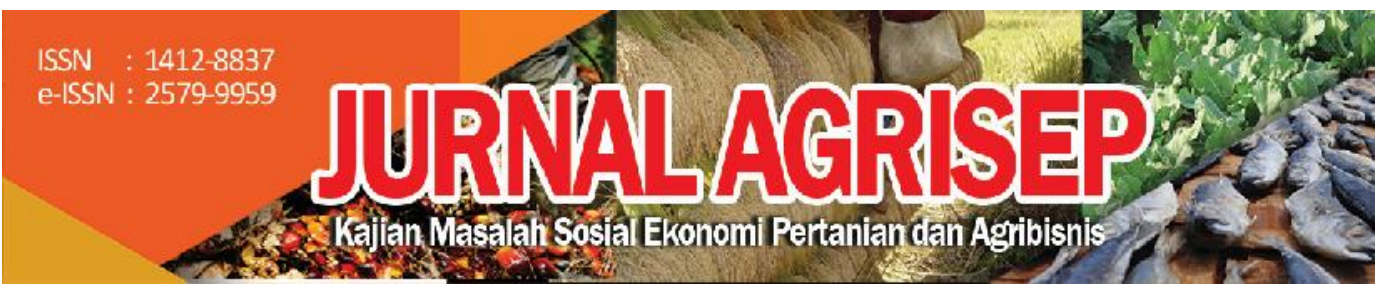

DOI: $10.31186 /$ jagrisep.18.2.305-312

\title{
ANALISIS PARTISIPASI DAN PERSEPSI MASYARAKAT PETANI TERHADAP RESTORASI DAN PRESERVASI HUTAN
}

\section{Analysis Of Farmer Participation And Perception Of Forest Restoration And Preservation}

\author{
Ana Nurmalia 区; Wahyu Handono \\ Program Studi Agribisnis Fakultas Pertanian, Universitas Dehasen Bengkulu, \\ E-mail: ananurmalia@unived.ac.id
}

\begin{abstract}
ABSTRAC
Polemics on forest damage and socio-economic problems that arise then what can be done to balance management as an element of economic support but still do not forget the importance is to actively participate in saving by restoration and preservation of forests. Researchers are interested in conducting a more in-depth study of "community participation and perceptions of forest restoration and preservation with a case study in Lubuk Pinang Village, Lubuk Pinang District, Mukomuko District, Bengkulu Province. The research was done intentionally (purposive) using secondary and primary data from the interview process and the existing literature, the process of taking samples using the census method, and using descriptive analysis. The results of research showed community participation in forest restoration and preservation included in the high category of 26,27 and community perceptions of forest restoration and preservation are included in the high category of 24.17. In this study there is harmony between the level of perception and participation of both of them into the high category.
\end{abstract}

Keywords: participation, perception, forest, restoration, preservation

\section{ABSTRAK}

Berbagai polemik kerusakan hutan dan masalah sosial ekonomi yang ditimbulkan maka yang bisa dilakukan untuk menyeimbangkan pengelolaan sebagai unsur pendukung ekonomi namun tetap tidak melupakan arti pentingnya adalah berpartisipasi aktif dalam menyelamatkan yaitu dengan melakukan restorasi dan preservasi hutan. Peneliti tertarik untuk melakukan kajian lebih mendalam tentang "partisipasi dan persepsi masyarakat terhadap restorasi dan preservasi hutan dengan studi kasus Di Desa 
Lubuk Pinang Kecamatan Lubuk Pinang Kabupaten Mukomuko Provinsi Bengkulu yang. Penelitian dilakukan secara sengaja (purposive) dengan menggunakan data sekunder dan primer dari proses wawancara dan literatur yang ada, proses pengambilan sampel menggunakan metode sensus, dan menggunakan analisa deskriptif.Hasil penelitian menunjukan partisipasi masyarakat terhadap restorasi dan preservasi hutan termasuk pada katagori tinggi yaitu sebesar 26,27 dan ersepsi masyarakat terhadap restorasi dan preservasi hutan termasuk pada katagori tinggi yaitu sebesar 24,17. Dalam penelitian ini terdapat keselarasan antara tingkat persepsi dan partisipasi keduanya masuk dalam kategori yang tinggi.

Kata Kunci: partisipasi, persepsi, hutan, restorasi, preservasi

\section{PENDAHULUAN}

Kerusakan hutan hampir terjadi di seluruh wilayah indonesia yang merupakan dampak dari buruknya keadaan sosial ekonomi masyarakat, kerusakan hutan yang paling banyak terjadi adalah pembabatan atau pembakaran hutan secara sengaja karena berbagai tujuan, salah satunya adalah pembukaan lahan baru untuk bercocok tanam maupun untuk pemukiman industri ataupun transmigrasi, hutan di ekspolrasi seolah-olah tidak mengerti pentingnya hutan bagi kehidupan.

Padahal manfaat hutan sangat besar yaitu merupakan paru paru dunia, mengurangi polusi, sumber ekonomi, habitat flor dan fauna, pengendali bencana, pengatur iklim bahkan pengatur tata air. Ekosistem hutan yang stabil mampu memberikan manfaat bagi pengatur tata air dan hidupan liar di dalamnya. Selain itu,ekosistem hutan yang stabil mampu memberikan sumber penghidupan bagi masyarakat sekitar dan di dalamnya. Masyarakat dapat mendapatkan kesejahteraan dengan memanfaatan secara lestari ekosistem hutan. Demikian halnya dalam perencanaan kegiatan rehabilitasi dan restorasi lanskap hutan, masyarakat harus berperan dan mendapatkan sumber pendapatan baru dari kegiatan restorasi lanskap hidup. Prinsip restorasi lanskap hutan selain mendapatkan kembali integritas fungsi ekologi, juga mewujudkan kesejahteraan masyarakat di dalam dan sekitar landskap hutan yang mengalami kerusakan (Samsuri, 2014).

Restorasi dan preservasi adalah suatu kegiatan mengembalikan dan menambah fungsi hutan seperti sebelum adanya kerusakan. Mengingat pentingnya hutan untuk keberlangsungan hidup manusia baik dari segi ekonomi, sosial dan kesehatan, maka di butuhkan berbagai partisipasi baik dari pemerintah, keterlibatan swasta dan masyarakat. Partisipasi dan persepsi masyarakat yang baik dalam restorasi dan preservasi hutan akan menumbuhkan pengalaman dan rasa memiliki yang dapat meningkatkan rasa tanggung jawab dan kemauan untuk melakukan pengelolaan secara berkelanjutan. Dimana yang merupakan unsur terpenting adalah masyarakat sehingga masyarakat harus

306 | Ana Nurmalia, Wahyu Handono ; Analisis Partisipasi dan Persepsi... 
memiliki partisipasi dan persepsi yang baik dalam restorasi dan pelestarian hutan guna kelangsungan hidup, memperbaiki dan meningkatkan kualitas sosial ekonomi masyarakat sekitar hutan khususnya dan manusia diseluruh dunia pada umumnya.

\section{METODE PENELITIAN}

Populasi dalam penelitian ini adalah kelompok tani hutan (KTH) Di Desa Lubuk yang terdapat $4 \mathrm{KTH}$ dengan total jumlah petani yang aktif adalah 140 orang, 21 dari KTH Sekehendak jaya, 61 orang dari KTH Muara Simpang, 47 dari KTH Mitra Setia dan 11 orang merupakan anggota KTH Rimba Lestari. Penentuan sample menggunakan metode sensus yaitu dengan melakukan pendataan seluruh anggota populasi dilokasi penelitian (Suyanto,2008).

Data yang digunakan dalam penelitian ini adalah data primer dan data sekunder yang dianalisa secara deskriptif setelah diajukan beberapa pertanyaan, sehingga diperoleh hasil yang lengkap dan terinci. Jawaban untuk mengetahui tingkat partisipasi yang diberikan berdasarkan tingkatannya dimana untuk jawaban ( $\mathrm{YS}$ = ya selalu, $\mathrm{KD}=$ kadang-kadang, dan TP = tidak pernah) Jawaban untuk mengetahui tingkat persepsi yang diberikan berdasarkan tingkatannya dimana untuk jawaban ( $\mathrm{S}=$ setuju, $\mathrm{KS}=$ kurang setuju, dan TS = tidak setuju).

Alternatif jawaban akan diberi nilai berdasarkan tingkatan (score) YS/S = $3, \mathrm{KD} / \mathrm{KS}=2$, dan $\mathrm{TP} / \mathrm{TS}=1$. Rentang nilai (range) masing-masing kategori dapat diketahui dengan menggunakan rumus sebagi berikut (Siegel, 2001):

$$
\text { Interval }=\frac{\text { nilai atas }- \text { nilai bawah }}{\text { jumlah kelas }}=\frac{30-7}{3}=7,6
$$

dimana: nilai atas adalah skor tertinggi (3) $x$ Jumlah pertanyaaan; nilai bawah adalah skor terendah (1) $\times$ Jumlah pertanyaan.

Kategori :

$$
\begin{array}{ll}
\text { Rendah/Kurang } & =7-14,6 \\
\text { Sedang/Cukup } & =14,7-22,3 \\
\text { Tinggi/Baik } & =22,4-30
\end{array}
$$

Untuk Penilaian setiap indikator $=$ Total Score per Indikator/Jumlah Responden.

\section{HASIL DAN PEMBAHASAN}

\section{Gambaran Umum}

Lubuk pinang adalah sebuah desa yang terletak di Kecamatan Lubuk Pinang Kabupaten Mukomuko Di Provinsi Bengkulu. Desa Lubuk Pinang berdampingan dengan Hutan Produksi Terbatas Air Majunto. Kecamatan Lubuk Pinang ditetapkan sebagai kawasan pertanian tanaman pangan oleh Pemerintah Kabupaten Mukomuko, sehingga hampir tidak ada industri seperti 
di kecamatan lainnya. Melihat hal tersebut membuat sebagian besar masyarakat bermata pencaharian sebagai petani dan beberapa melakukan perambahan di dalam HPT Air majunto Hal ini dibuktikan dengan berita dari salah satu media yaitu Bengkulu Express pada tahun 2015 yang memberitakan pembalakan liar di Kabupaten Mukomuko semakin marak. Kantor Kesatuan Pengelolaan Hutan Produksi (KPHP) Kabupaten Mukomuko, berhasil mengamankan sekitar empat kubik kayu jenis meranti dan rimba campuran. Kayu yang berasal dari hutan produksi terbatas (HPT) Majunto.

Kegiatan Restorasi dan preservasi di lakukan oleh pemerintah baik pemerintah pusat maupun daerah yang bekerja sama dengan pihak swasta dan masyarakat. Selain itu kawasan tersebut sebelumnya pernah menjadi bagian dari IUPHHK-HA (Izin usaha pemanfaatan hasil hutan kayu- hutan alam) sehingga lebih mudah diakses atau dirambah oleh masyarakat dan membuat ekosistem kawasan tersebut menjadi rusak. Menurut Senoaji (2011) keterbatasan lahan yang dimiliki oleh masyarakat di sekitar hutan akan berakibat pada kondisi hutan di sekelilingnya. Mereka akan menggantungkan hidupnya pada hutan yang ada di sekeliling pemukimannya guna memenuhi kebutuhan hidup yang terus meningkat.

Upaya untuk mengembalikan fungsi dari Hutan Produksi Terbatas Air Majunto tersebut adalah dengan merangkul masyarakat untuk ikut mensukseskan kegiatan restorasi dan preservasi. Selain itu mensosialiasikan kegiatan restorasi dan preservasi kepada masyarakat tani yaitu berupa pengelolaan hutan yang memberikan kesempatan masyarakat petani sekitar untuk memanfaatkan lahan hutannya sesuai dengan sesuai dengan Permenhut No.39 Tahun 2013 tentang Pemberdayaan Masyarakat Setempat melalui Kemitraan Kehutanan dan P.83/2016 Permen LHK tentang Perhutanan Sosial.Upaya lainnya adalah sosialisasi mengenai larangan berburu. Hal ini berkaitan dengan HPT Air Majunto sebagai habitat Harimau Sumatera yang mana kawasan tersebut berbatasan langsung dengan TNKS (Taman Nasional Kerinci Seblat) yang juga menjadi habitat dari Harimau Sumatera.

Masyarakat petani yang sebelumnya adalah perambah hutan beralih menjadi penggarap hutan dalam bentuk kelompok tani yang mengelola hutan secara resmi yaitu 2 hektar per anggota kelompok tani dengan ketentuan 60 persen tanaman kayu - kayuan yang berupa kayu bawang, meranti, medang dan lain lain, 40 persennya adalah MPTS (Multi Purpose Tree Species). MPTS itu sendiri adalah jenis tanaman yang menghasilkan kayu dan bukan kayu yaitu getah, buah, daun, bunga, serat, pakan ternak, dan sebagainya (Permenhut,2014). Selain itu kegiatan tersebut memperhitungkan jenis tanaman, jarak tanam, dilaksanakan dengan pembentukan kelembagaan terlebih dahulu, pelatihan, penyiapan bibit, penanaman, pendampingan, monitoring dan evaluasi.

308 | Ana Nurmalia, Wahyu Handono ; Analisis Partisipasi dan Persepsi... 


\section{Tingkat Partisipasi Masyarakat Terhadap Restorasi Dan Preservasi Hutan}

Hasil wawancara dengan 140 responden menunjukkan bahwa rata-rata tingkat partisipasi masyarakat termasuk pada katagori tinggi yaitu sebesar 26,27 hal ini. Sebagian besar responden melakukan kegiatan restorasi dan preservasi hutan produksi terbatas berdasarkan keinginan sendiri. Hal ini dapat terlihat dari berjalannya kegiatan restorasi dan preservasi dengan baik. Hal ini berbanding terbalik dengan penelitian (Damanik,2013) yang mana tingkat partisipasi masyarakat dalam pengelolaan Tahura Bukit Barisan, Kawasan Hutan Sibayak II, Kabupaten Karo berada pada kategori rendah, dibuktikan dengan tingkat kehadiran masyarakat yang rendah dalam setiap jenis kegiatan mengakui bahwa mereka masih memiliki kepentingan dengan hutan untuk kebutuhan sehari-hari namun masyarakat memiliki pemahaman bahwa sudah ada pihak-pihak tertentu yang memiliki wewenang untuk mengelola hutan secara lestari. Hal ini sesuai dengan pernyataan Ngakan, dkk (2006) yang menyatakan bahwa berpartisipasi pasif ialah apabila mereka berpikir bahwa harus dilakukan upaya-upaya untuk menjaga keberlanjutan ketersediaan sumber daya hayati hutan di sekitar kampung mereka, tetapi mereka tidak pernah terlibat aktif dan berharap agar pemerintah atau pihak lain yang melakukannya.

Dalam menganalisis tingkat persepsi digunakan 10 indikator yaitu keikutsertaan dalam pengelolaan kawasan berdasarkan keinginan petani itu sendiri, keikutsertaan berdasarkan pengalaman dan ilmu yang petani miliki, keikutsertaan berdasarkan ilmu dan manfaat yang akan diterima, keikutsertaan dalam kegiatan perencanaan, sosialisasi, pelaksanaan, serta keikutsertaan dalam kegiatan monitoring dan evaluasi restorasi dan preservasi, menerima putusan yang dikeluarkan dalam setiap kegiatan pengelolaan kawasan, melaksanakan setiap putusan yang dikeluarkan dalam setiap kegiatan pengelolaan kawasan, memberikan pendapat atau masukan dalam setiap kegiatan restorasi dan preservasi.

Secara keseluruhan nilai partisipasi KTH terhadap kegiatan restorasi dan preservasi termasuk dalam kategori tinggi, apabila dilihat per indikator nilai yang menunjukkan partisipasi tertinggi ada dua indikator yang memiliki nilai sebesar 2,807 yaitu indikator dimana keikutsertaan dalam kegiatan pengelolaan perdasarkan pengalaman dan ilmu yang telah petani hutan miliki, hal ini disebabkan masyarakat petani tinggal di sekitar Kawasan Hutan Produksi Terbatas Air Majunto sehingga telah memiliki pengalaman yang lama dalam melakukan pengelolaan kawasan hutan. Indikator ke dua yang mana masyarakat petani melaksanakan setiap putusan yang dikeluarkan dalam setiap kegiatan pengelolaan kawasan, hal ini dijelaskan oleh sebagian besar responden dimana mereka akan melaksanakan setiap komando dari koordinator lapangan baik dari pihak pemerintah maupun swasta. 
Indikator yang memiliki nilai terendah adalah partisipasi dalam kegiatan monitoring evaluasi kegiatan pengelolaan kawasan hutan sebesar 2,114 . hal ini dikarenakan kegiatan monev tidak selalu diadakan serentak sehingga tidak semua petani dapat hadir, namun dalam kegiatan ini selalu ada kordinasi dari pemerintah dan swasta ke ketua kolompok tani hutan, sehingga ketua selalu menyampaikan hasil dan keputusan, dan rekomendasi ke pada setiap anggotanya sehingga tetap terjalin koordinasi yang baik. Variable terendah dengan nilai 2,164 disusul oleh indikator yang menilai keikutsertaan para petani dalam menyatakan pendapat atau masukan selama kegiatan berlangsung baik saat perencanaan, sosialisasi, pelaksanaan, maupun saat monitoring evaluasi, tidak semua petani berani dan mau menyatakan pendapat mereka, sebagian hanya menerima keputusan dari koordinator lapangan dan dari para ketua kelompok tani hutan.

Dominan para anggota KTH berpartisipasi dalam kegiatan ini adalah atas keinginan sendiri, mereka terdorong untuk berpartisipasi karena terdorong untuk mengelola kawasan dan ekosistem hutan yang sudah semakin rusak dan perlu restorasi dan preservasi, alasan selanjutnya adalah dengan mengikuti kegiatan pengelolaan ini masyarakat mendapat penghasilan tambahan dari pola kemitraan serta berbagai ilmu dalam bertani, melakukan resorasi dan preservasi hutan. Masyarakat petani pun sangat kooperatif menerima dan melaksanakan setiap keputusan dan peraturan yang disampaikan dalam kegiatan, selain itu sebagian besar para petani berpartisipasi langsung dalam kegiatan perencanaan, sosialisasi, dan pelaksaan.

\section{Tingkat Persepsi Masyarakat Terhadap Restorasi Dan Preservasi Hutan}

Nilai total rata - rata persepsi masyarakat terhadap restorasi dan preservasi hutan termasuk pada katagori tinggi yaitu sebesar 24,17. Hal ini menunjukkan tingginya tingkat persepsi masyarakat dalam pengelolaan kawasan hutan . Hal ini sejalan dengan penelitian firdaus pada tahun 2015 yang menyatakan persepsi masyarakat terhadap fungsi hutan kota di lingkungan padat penduduk dapat di simpulkan adalah baik.

Dalam menganalisis tingkat persepsi masyarakat petani digunakan 10 indikator yaitu pandangan petani terhadap Kawasan Hutan Air Majunto sebagai hutan produksi terbatas, pengelolaan kawasan (restorasi dan preservasi), pengelolaan (restorasi dan preservasi) di Kawasan Hutan Air Majunto, pihak yang terlibat dalam kegiatan pengelolaan, kegiatan perencanaan, sosialisasi, pelaksanaan dan monitoring evaluasi kegiatan restorasi dan preservasi apakah sudah sesuai dengan permenhut, kegiatan pengelolaan berdampak positif bagi kehidupan para petani, dan yang terakhir adalah pandangan masyarakat petani terhadap kegiatan pengelolaan berdampak positif bagi ekosistem kawasan.

Berdasarkan rata-rata total tingkat persepsi termasuk katagori tinggi, namun untuk nilai persepsi perindikator terjadi fluktuatif yang tertinggi adalah

310 | Ana Nurmalia, Wahyu Handono ; Analisis Partisipasi dan Persepsi... 
senilai 2,80 yaitu indikator pandangan masyarakat petani terhadap kawasan yang berstatus hutan produksi terbatas, sebagian besar responden paham dan setuju kawasan tersebut berstatus HPT, mereka menganggap wilayah kabupaten Mukomuko sebagian besar telah beralih fungsi lahan menjadi kebun sawit yang tidak ramah lingkungan, sehingga penting nya keberadaan hutan air majunto ini yang berstatus hutan produksi terbatas akan membatasi eksploitasi kawasan hutan dan ekosistem akan lebih terjaga.

Indikator yang memiliki nilai terendah dengan range 2,06 - 2,38 ada empat indikator dengan yaitu pandangan petani hutan terhadap kesesuaian kegiatan perencanaan, sosialisasi, pelaksanaan dan monitoring evaluasi kegiatan restorasi dan preservasi dengan permenhut. Disini sebagian responden menjelaskan jika mereka kurang paham mengenai dasar dari kegiatan pengelolaan tersebut, namun mereka akan menerima setiap perintah dan melaksanakan setiap arahan dari koordinator yang merupakan perwakilan dari pihak pemerintah maupun swasta.

Sebagian besar para petani memiliki pemahaman yang baik mengenai kegiatan restorasi dan preservasi, responden memahami jika kegiatan ini bertujuan untuk mengembalikan dan menambah fungsi serta melestarikan hutan. Karena pemahaman tersebut para petani setuju dan berpartisipasi untuk melakukan restorasi dan preservasi guna memperbaiki, menambah fungsi, serta melestarikan ekosistem Kawasan HPT Air Majunto. Sebagian Masyarakat petani pun sudah merasakan berbagai manfaat dari kegiatan ini, diantaranya adalah bertambahnya penghasilan mereka dari lahan hutan resmi yang mereka kelola, bahkan setelah mendapatkan berbagai ilmu dari sosialisasi kegiatan ini masyarakat tidak lagi berburu, mereka bekerja sama dengan tim patroli untuk mensukseskan dan mensosialisasikan larangan berburu ke lingkungan sekitar yang mana berburu akan merusak rantai makanan, menyebabkan kepunahan satwa bahkan hewan predator dapat memangsa hewan ternak bahkan manusia jika rantai makanan tersebut rusak.

Dengan terciptanya persepsi yang benar maka program-program yang dirancangkan dan dilaksanakan dapat berjalan baik, terjadi partisipasi yang baik, dan akan mendapatkan hasil yang di harapkan. Dalam penelitian ini tingkat persepsi dan partisipasi keduanya masuk dalam kategori yang tinggi.

\section{SIMPULAN DAN SARAN}

\section{Simpulan}

Partisipasi masyarakat terhadap restorasi dan preservasi hutan termasuk pada katagori tinggi yaitu sebesar 26,27. Persepsi masyarakat terhadap restorasi dan preservasi hutan termasuk pada katagori tinggi yaitu sebesar 24,17. 


\section{Saran}

Untuk meningkatkan partisipasi masyarakat terhadap restorasi dan preservasi hutan yang sudah dalam katagori tinggi yaitu dengan mendorong masyarakat untuk lebih aktif daalam kegiatan monev dan mengutarakan pendapat tanpa melalui perwakilan. Untuk meningkatkan persepsi masyarakat terhadap restorasi dan preservasi hutan yang sudah dalam katagori tinggi yaitu meningkatkan pengetahuan masyarakat tentang dasar hukum kegiatan ini agar masyarakat semakin mendalami makna dan aturan aturan yang berlaku melalui penyuluhan.

\section{DAFTAR PUSTAKA}

Damanik, R.N. 2013. Persepsi dan Partisipasi Masyarakat Terhadap Sumber Daya Hutan (Studi Kasus Tahura Bukit Barisan, Kawasan Hutan Sibayak II, Kabupaten Karo). Universitas Sumatera Utara. Medan.

Firdaus. 2015. Persepsi Masyarakat Terhadap hutan Kota di Lingkungan Padat Penduduk. Skripsi. Jakarta: Jurusan pendidikan Ilmu Pengetahuan Sosial Fakultas Ilmu Tarbiyah dan Keguruan UIN Syarif Hidayatullah. Hasbullah, 2003. Dasar-dasar Ilmu Pendidikan. Jakarta: PT. Raja Grafindo Persada

Ngakan, Putu Oka., H. Komarudin, A. Achmad, Wahyudi, dan A.Tako. 2006. Ketergantungan, Persepsi dan Partisipasi Masyarakat terhadap Sumberdaya Hayati Hutan Studi Kasus di Dusun Pampli Kabupaten Luwu Utara, Sulawesi Selatan. CIFOR. Jakarta.

Peraturan menteri kehutanan No. P.16/Menhut-. II/2014 tentang Pedoman Penanaman Bagi Pemegang Izin Pinjam Pakai Kawasan Hutan Dalam Rangka Rehabilitasi Daerah Aliran Sungai

Peraturan menteri kehutanan No.39 Tahun 2013 tentang Pemberdayaan Masyarakat Setempat melalui Kemitraan Kehutanan

Permen LHK No P.83/2016 tentang Perhutanan Sosial.

Samsuri.2014. Model Spasial Indeks Restorasi Lanskap Hutan Tropis Terdegradasi Daerah Aliran Sungai Batang Toru Sumatera Utara. Thesis. Bogor Agricultural University.

Senoaji, G. 2011. Kondisi Sosial Ekonomi Masyarakat Sekitar Hutan Lindung Bukit Daun Di Bengkulu. Jurnal Sosiohumaniora, Volume 13, No. 1.

Suyanto.2008. Prosedur Penelitian Suatu Pendekatan Praktek. Jakarta: Rineka Cipta

312 | Ana Nurmalia, Wahyu Handono ; Analisis Partisipasi dan Persepsi... 